\title{
Sildenafil improves heart rate variability in dogs with asymptomatic myxomatous mitral valve degeneration
}

\author{
Prapawadee PIRINTR ${ }^{1,2)}$, Nakkawee SAENGKLUB ${ }^{3)}$, Vudhiporn LIMPRASUTR ${ }^{1)}$, \\ Suwanakiet SAWANGKOON ${ }^{11}$ and Anusak KIJTAWORNRAT ${ }^{1,4) *}$
}
1)Department of Physiology, Faculty of Veterinary Science, Chulalongkorn University, Henri Dunant Road, Pathumwan, Bangkok 10330, Thailand
2)Department of Veterinary Bioscience and Veterinary Public Health, Faculty of Veterinary Medicine, Chiang Mai University, Mae Hia, Muang, Chiang Mai 50100, Thailand
3) Department of Physiology, Faculty of Pharmacy, Mahidol University, Sri Ayudhya Road, Rajathevi, Bangkok 10400, Thailand
4) Research Clusters: Research Study and Testing of Drug's Effect Related to Cardiovascular System in Laboratory Animal, Chulalongkorn University, Henri Dunant Road, Pathumwan, Bangkok 10330, Thailand

\section{J. Vet. Med. Sci.}

79(9): 1480-1488, 2017

doi: 10.1292/jvms.17-0016

Received: 16 January 2017

Accepted: 4 July 2017

Published online in J-STAGE:

17 July 2017
ABSTRACT. Myxomatous mitral valve degeneration (MMVD) causes an imbalance of sympathovagal activity resulted in poor cardiac outcomes. Phosphodiesterase- 5 inhibitors have been revealed cardioprotective effect in patients with heart diseases. This study aimed to 1) compare the heart rate variability (HRV) between asymptomatic MMVD and healthy dogs and 2) assess long-term effects of sildenafil and enalapril on time- and frequency-domains analyzes. Thirty-four dogs with MMVD stage B1 or B2 and thirteen healthy dogs were recruited into the study. MMVD dogs were divided into 3 subgroups: control $(n=13)$, sildenafil $(n=12)$ and enalapril $(\mathrm{n}=9)$. HRV was analyzed from 1-hr Holter recording at baseline (D0) in all dogs and at 30,90 and 180 days after treatment. The results showed that MMVD dogs had significant higher heart rate (HR), systemic blood pressures, the ratio of low to high frequency (LF/HF) and had significant decreased standard deviation of all normal to normal RR intervals (SDNN) and the percentage of the number of normal-to-normal sinus RR intervals with differences $>50 \mathrm{msec}$ computed over the entire recording ( $p N N 50)$ when compared with healthy dogs $(P<0.05)$. Neither time nor frequency domain parameters were different among subgroups of MMVD dogs at DO. After treatment with sildenafil for 90 days, both time- and frequency-domain parameters were significantly increased when compared with control and enalapril groups. This study demonstrated that sildenafil improves HRV in asymptomatic MMVD dogs suggesting that sildenafil should be used in the MMVD dogs to restore the sympathovagal balance.

KEY WORDS: dog, enalapril, heart rate variability, myxomatous mitral valve degeneration, sildenafil

Myxomatous mitral valve degeneration (MMVD) is the most common acquired heart disease in small breed, aging dogs [15]. When the valve is leaking, the backward flow of blood from left ventricle into the left atrium activates several compensatory mechanisms including the sympathetic nervous system (SNS) and the renin-angiotensin aldosterone system (RAAS) [33]. In small animal veterinary medicine, the current data indicate that there are no effective drugs for preventing the progression of MMVD. Once the clinical signs develop, angiotensin converting enzyme inhibitor (ACEi), diuretic and inodilator are recommended [3].

Heart rate variability (HRV) is a quantitative marker that had been clinically used as a standard screening method for detection of cardiac autonomic nervous system (CANS) activity [30]. Reduced HRV has prognostic significance for mortality in congestive heart failure (CHF) population [16]. Changing of the sympathetic and/or parasympathetic activity of the heart could be assessed through the time- and frequency-domain parameters of HRV [30]. In patients and dogs with CHF, the progression of cardiac diseases promote alterations in the cardiac autonomic function often expressed as a sympathovagal imbalance leading to an increase in heart rate and a decrease in HRV [20,31]. Previous publications indicated that HRV is very sensitive tool for detecting mild mitral regurgitation (MR) in dogs before the onset of clinical signs suggesting the benefit of using this tool for treatment follow up $[14,24]$. Recent clinical trial in MMVD dogs with moderate to severe MR suggested that enalapril could delay the onset

*Correspondence to: Kijtawornrat, A.: Anusak.k@chula.ac.th

O2017 The Japanese Society of Veterinary Science

This is an open-access article distributed under the terms of the Creative Commons Attribution Non-Commercial No Derivatives (by-nc-nd) License. (CC-BY-NC-ND 4.0: https://creativecommons.org/licenses/by-nc-nd/4.0/) 
of CHF [4]. However, the data of chronic treatment with enalapril on HRV in MMVD dogs are not available.

Sildenafil is a selective phosphodiesterase-5 inhibitor (PDE5i) causing nitric oxide-mediated vasodilation [32]. In veterinary medicine, sildenafil is widely used for the treatment of pulmonary arterial hypertension (PAH) [7]. Recently, sildenafil has been demonstrated to delay ventricular remodeling in humans and experimental animals induced by volume or pressure overload as well as heart failure [11]. However, effects of sildenafil on autonomic nervous function in MMVD dogs have not been investigated.

Because autonomic imbalance resulting from sympathetic over activity and/or parasympathetic withdrawal is a characteristic feature of CHF, this study hypothesized that early treatment with sildenafil may improve HRV in dogs with asymptomatic MMVD. The aims of this study were to 1) compare the HRV between asymptomatic MMVD and healthy dogs and 2) assess chronic effects of sildenafil and enalapril on time- and frequency-domains analyzes of HRV in MMVD dogs.

\section{MATERIALS AND METHODS}

\section{Animals}

A total of 52 privately client-owned dogs, being older than 6 years and had not heart failure or received any drugs that affected heart rate variability such as $\alpha$ and $\beta$ blockers were recruited into the study. All dogs underwent clinical examination and cardiac auscultation to diagnose MMVD. If systolic murmur was audible at left apex area with no clinical sign of CHF, echocardiogram and thoracic radiograph would be investigated to confirm the present of MR and to classify the stage of cardiac diseases according to the American College of Veterinary Internal Medicine (ACVIM) [3]. Only healthy dogs and dogs with MR in the stage B1 or B2 and the diameter of left atrium (LA) and aortic root (AO) (LA/AO) was greater than 1.13 were enrolled for further investigation [6]. Five dogs were excluded from the study because of second degree AV block $(n=1)$, mammary gland tumor $(n=2)$, present with syncope before the end of study $(n=1)$ and client incompliance $(n=1)$.

\section{Experimental protocol}

This study was approved by the Institutional Animal Care and Use Committee, Faculty of Veterinary Science, Chulalongkorn University (protocol no.1431008). A total of 47 privately client-owned dogs, healthy and asymptomatic MMVD dogs, were examined with consent from owners at the Cardiac Unit, Small Animal Teaching Hospital, Faculty of Veterinary Science, Chulalongkorn University. Dogs were divided into 2 groups according to their health status. Group 1 (healthy dogs): the 13 clientowned healthy dogs and Group 2 (MMVD dogs): the 34 client-owned asymptomatic MR dogs with ACVIM class B1 or B2. The dogs in MMVD group were further divided into 3 subgroups: Group 2A; the MMVD control group (n=13), Group 2B; MMVD sildenafil group $(n=12)$ and Group 2C; the MMVD enalapril group ( $n=9)$. In each group (2A, 2B and 2C), the severity MMVD was distributed equally. All dogs underwent clinical examination, cardiac auscultation, blood pressure measurement, electrocardiograms (ECG), blood collection for complete blood count and serum chemistry profiles including blood urea nitrogen, creatinine, serum glutamic pyruvic transaminase, alkaline phosphatase and $1 \mathrm{hr}$ of Holter monitoring while they were at rest in a quiet environment for collected the baseline data. Noninvasive BP measurements was performed by using an oscillometric device (petMAPTM, CardioCommand, Inc., Tampa, FL, U.S.A.). A pressure cuff of appropriate width (i.e. $-40 \%$ of the leg's circumference) was placed at left forelimb upon the median artery between the elbow and the carpal pad. Five consecutive measurements of blood pressure were obtained and the average of 3 consistent BP was used for calculation. The MMVD dogs that were enrolled in this study were further subjected to measurement of blood pressure, $1 \mathrm{~min}$ ECG and $1 \mathrm{hr}$ of Holter recording. The dogs were divided into three subgroups: control, sildenafil and enalapril. Since there is no consensus on the standard protocols for treatment of stage B1 and B2 MMVD dogs, owners made decisions with the veterinarian whether or not to supplement their dogs with sildenafil or enalapril [2]. After baseline data (day 0) were obtained, dogs in sildenafil groups were given sildenafil (Sidegra ${ }^{\circledR}, 50 \mathrm{mg} / \mathrm{tab}$, The Government Pharmaceutical Organization, Bangkok, Thailand) orally at a dose of 1-3 mg/kg, twice a day for 180 days whereas dogs in enalapril groups were given enalapril (Anapril ${ }^{\circledR}, 5 \mathrm{mg} / \mathrm{tab}$, Berlin Pharmaceutical Industry, Bangkok, Thailand) orally at a dose of $0.25 \mathrm{mg} / \mathrm{kg}$, twice a day for 180 days. Doses of sildenafil and enalapril were chosen according to the recommended therapeutic dose in dogs $[4,17]$. Dogs in the control group did not receive any treatment and were monitored at the same time as dogs in other groups. All MMVD dogs were re-evaluated for blood pressure measurement, 1 min ECG and $1 \mathrm{hr}$ of Holter recording at day 30, 90 and 180 after receiving the first treatment. Dogs were considered to have reached the endpoint of the study when one of the following occurred: increased the stage of MMVD, drug intolerance or end of study period (180 days).

\section{Experimental procedures}

Holter recordings: Holter recording were obtained continuously $1 \mathrm{hr}$ from non-sedated, resting without sleeping dogs while they were stayed in a quiet room with owner. Standard 3 channels ECG electrodes were attached on to the chest wall of the dog and connected to Holter device (Fukuda Denshi Co., Tokyo, Japan). Clients were advised to give medicine to the dogs at least $1 \mathrm{hr}$ before the beginning of recording. The time for recording was arranged to perform between 10:00 am to 12:00 pm.

Data Analysis: All cardiac cycles obtained from Holter recording were manually edited by using SCM-510 program (Fukuda Denshi Co.). The data obtained from 6 consecutive 10-min sections were averaged and used in the study. Heart rate variability parameters were analyzed for both time- and frequency-domain (512 sec, Hamming window) as described previously [23]. Time domain parameters were shown in Table 1. Frequency domain ranges were set as low frequency (LF, 0.041-0.15 Hz), high frequency (HF, $0.15-0.5 \mathrm{~Hz}$ ), and total power $(0-0.5 \mathrm{~Hz})$. The ratio of LF to HF (LF/HF) quantified the change in the relationship between sympathetic and parasympathetic nerve activities (i.e. sympathovagal balance) was also calculated. The ranges of 
Table 1. Description of time domain parameters of heart rate variability (modified from Pirintr and colleagues, 2012)

\begin{tabular}{|c|c|c|}
\hline Parameters & Units & Description \\
\hline NNA (Mean NN) & $\mathrm{msec}$ & the average of normal sinus RR intervals in the entire recording \\
\hline SDNN & msec & standard deviation of all normal sinus RR intervals in the entire recording \\
\hline SDANN & msec & standard deviation of the average of normal sinus RR intervals in division of the entire recording \\
\hline SDNN index & msec & the average of the standard deviation of all normal sinus RR intervals in division of the entire recording \\
\hline pNN50 & $\%$ & $\begin{array}{l}\text { the percentage of the number of normal-to-normal sinus RR intervals with differences }>50 \text { msec computed } \\
\text { over the entire recording }\end{array}$ \\
\hline rMSSD & msec & $\begin{array}{l}\text { square root of the average of the squared differences between adjacent normal sinus RR intervals over the } \\
\text { entire recording }\end{array}$ \\
\hline
\end{tabular}

Table 2. Baseline characteristics of the study population

\begin{tabular}{|c|c|c|c|c|}
\hline \multirow[b]{2}{*}{ Variables } & \multirow{2}{*}{$\begin{array}{l}\text { Healthy dogs } \\
\qquad(n=13)\end{array}$} & \multicolumn{3}{|c|}{ MMVD dogs $(n=34)$} \\
\hline & & $\begin{array}{l}\text { Control group } \\
\qquad(\mathrm{n}=13)\end{array}$ & $\begin{array}{l}\text { Sildenafil group } \\
(\mathrm{n}=12)\end{array}$ & $\begin{array}{c}\text { Enalapril group } \\
(\mathrm{n}=9)\end{array}$ \\
\hline Age (years) & $9.8 \pm 0.7^{\mathrm{a})}$ & $13.0 \pm 0.8^{\mathrm{b})}$ & $12.4 \pm 0.9^{\mathrm{ab})}$ & $12.3 \pm 0.9^{\mathrm{ab})}$ \\
\hline Weight $(\mathrm{kg})$ & $5.8 \pm 0.4$ & $6.0 \pm 0.9$ & $6.2 \pm 1.0$ & $6.3 \pm 0.7$ \\
\hline \multicolumn{5}{|l|}{ Breeds } \\
\hline Poodle & 10 & 5 & 4 & 5 \\
\hline Pomeranian & 2 & 2 & 2 & \\
\hline Shih Tzu & 1 & 2 & 3 & 2 \\
\hline Yorkshire Terrier & & & 2 & 1 \\
\hline Miniature Pinscher & & 1 & & \\
\hline Beagle & & 1 & 1 & \\
\hline Small mixed breed & & 2 & & 1 \\
\hline \multicolumn{5}{|l|}{ Gender } \\
\hline $\mathrm{M} / \mathrm{Mc} / \mathrm{F} / \mathrm{Fs}$ & $6 / 2 / 2 / 3$ & $5 / 2 / 0 / 6$ & $3 / 1 / 3 / 5$ & $4 / 2 / 1 / 2$ \\
\hline $\begin{array}{l}\text { Classify the stage of cardiac } \\
\text { diseases (ACVIM) }\end{array}$ & No & & & \\
\hline B1 & & 9 & 10 & 7 \\
\hline B2 & & 4 & 2 & 2 \\
\hline
\end{tabular}

Data are presented as mean \pm SEM. a, b) compared the age among groups (i.e. Healthy, Control, Sildenafil and Enalapril) within the same row of table, statistical difference $(P<0.05), M M V D$ myxomatous mitral valve degeneration; $M$ male; $M c$ castrate male; $F$ female; $F$ s spayed female.

frequency domain and the sympathovagal balance analyzed by power spectral for dogs were analyzed according to previous studies in dogs $[10,23]$.

\section{Statistics}

Statistical analysis was performed by use of commercially available software. Values were expressed as mean \pm standard error of mean (SEM). Data between MMVD dogs and healthy dogs were compared using Student's $t$-test. In each subgroup of MMVD dogs, percent changes from baseline were assessed. The data among subgroups (control, sildenafil and enalapril) of MMVD dogs at the same re-evaluation period (D0, D30, D90 and D180) were compared using one way ANOVA followed by Tukey's post hoc test. Statistical significance was considered when $P$-values were less than 0.05 .

\section{RESULTS}

Forty-seven privately owned small breed dogs weighing between $2-15 \mathrm{~kg}$ were included in the study. The baseline characteristics of the study population were showed in Table 2. None of these dogs had heart failure or received diuretic and any antiarrhythmic drugs that affected HRV. All healthy and MMVD dogs were older than 6 years (healthy: 6.4-14.8 years; MMVD: 6-18 years, respectively). Only the mean age of MMVD control group was significantly higher than that in healthy group $(P<0.05)$; however, the mean ages among MMVD groups were not different. More than 50 percent of dogs in this study were poodle. For the gender, the ratio of female to male in the healthy group, control, sildenafil and enalapril groups were $0.63: 1,0.86: 1,2: 1$ and $0.5: 1$, respectively. In the study, the average dose of sildenafil was $1.92 \mathrm{mg} / \mathrm{kg}$ (ranging between 1.34 and $2.87 \mathrm{mg} / \mathrm{kg}$ ) and enalapril was $0.28 \mathrm{mg} / \mathrm{kg}$ (ranging from 0.14 to $0.40 \mathrm{mg} / \mathrm{kg}$ ). One of control dog was increased the stage of MMVD before D90 and four more dogs after D90 measurement. In enalapril group, two dogs were increased the stage of MMVD dog before D90 (n=1) and after D90 
Table 3. Grade of systolic murmur, baseline heart rate, systolic, diastolic and mean blood pressures of the study population at baseline (D0)

\begin{tabular}{lccccc}
\hline \multicolumn{1}{c}{ Variables } & $\begin{array}{c}\text { Healthy dogs } \\
(\mathrm{n}=13)\end{array}$ & $\begin{array}{c}\text { MMVD dogs } \\
(\mathrm{n}=34)\end{array}$ & $\begin{array}{c}\text { Control group } \\
(\mathrm{n}=13)\end{array}$ & $\begin{array}{c}\text { Sildenafil group } \\
(\mathrm{n}=12)\end{array}$ & $\begin{array}{c}\text { Enalapril group } \\
(\mathrm{n}=9)\end{array}$ \\
\hline $\begin{array}{l}\text { Grade of systolic murmur } \\
\text { (from auscultation) }\end{array}$ & No & & & & \\
$\quad$ II / VI & & 12 & 6 & 4 & 3 \\
$\quad$ III / VI & & 9 & 3 & 3 & 4 \\
$\quad$ IV/VI & $96 \pm 3.4$ & $120 \pm 4.7^{\text {a) }}$ & $113 \pm 5.2$ & $118 \pm 8.2$ & $132 \pm 9.8$ \\
HR (bpm) & $114.3 \pm 4.0$ & $134.1 \pm 3.6^{\text {a }}$ & $130.6 \pm 5.7$ & $134.7 \pm 6.7$ & $138.4 \pm 7.2$ \\
SBP (mmHg) & $65.7 \pm 3.4$ & $87.0 \pm 2.9^{\text {a) }}$ & $84.9 \pm 4.6$ & $88.1 \pm 5.8$ & $88.8 \pm 5.6$ \\
DBP (mmHg) & $81.9 \pm 3.1$ & $107.0 \pm 3.2^{\text {a) }}$ & $104.4 \pm 5.2$ & $107.9 \pm 5.4$ & $109.8 \pm 6.5$ \\
MBP (mmHg) & & & & & \\
\hline
\end{tabular}

Data are presented as mean \pm SEM; heart rate was obtained from holter recording. a) $P<0.05$ compared between healthy and MMVD dogs, statistical difference $(P<0.05), M M V D$ myxomatous mitral valve degeneration; $H R$ heart rate; $S B P$ systolic blood pressure; $D B P$ diastolic blood pressure; $M B P$ mean blood pressure.

Table 4. Heart rate, systolic, diastolic and mean blood pressures in myxomatous mitral valve degeneration (MMVD) dogs measure at baseline (days 0), day 30, 90 and 180

\begin{tabular}{|c|c|c|c|c|c|}
\hline \multirow{2}{*}{\multicolumn{2}{|c|}{ Groups }} & \multirow{2}{*}{ Heart rate (bpm) } & \multicolumn{3}{|c|}{ Blood pressure $(\mathrm{mmHg})$} \\
\hline & & & SBP & DBP & MBP \\
\hline \multirow[t]{4}{*}{ Control } & D0 $(n=13)$ & $113 \pm 5.2$ & $130.6 \pm 5.7$ & $84.9 \pm 4.6$ & $104.4 \pm 5.2$ \\
\hline & D30 $(n=13)$ & $117 \pm 6.1$ & $130.8 \pm 6.0$ & $81.2 \pm 4.6$ & $103.8 \pm 6.1$ \\
\hline & D90 $(n=12)$ & $117 \pm 6.1$ & $128.6 \pm 5.3$ & $78.1 \pm 4.9$ & $99.9 \pm 5.5$ \\
\hline & $\mathrm{D} 180(\mathrm{n}=8)$ & $94 \pm 5.0$ & $137.6 \pm 5.4$ & $96.2 \pm 6.7$ & $113.0 \pm 6.7$ \\
\hline \multirow[t]{4}{*}{ Sildenafil } & D0 $(n=12)$ & $118 \pm 8.2$ & $134.7 \pm 6.7$ & $88.0 \pm 5.8$ & $107.9 \pm 5.4$ \\
\hline & $\mathrm{D} 30(\mathrm{n}=12)$ & $106 \pm 6.1$ & $136.2 \pm 7.3$ & $97.9 \pm 10.1$ & $113.6 \pm 8.1$ \\
\hline & D90 $(n=12)$ & $103 \pm 6.7$ & $129.6 \pm 4.6$ & $76.7 \pm 3.5$ & $98.8 \pm 3.8$ \\
\hline & $\mathrm{D} 180(\mathrm{n}=11)$ & $114 \pm 6.8$ & $131.6 \pm 6.8$ & $82.0 \pm 5.8$ & $102.8 \pm 5.3$ \\
\hline \multirow[t]{4}{*}{ Enalapril } & D0 $(n=9)$ & $132 \pm 9.8$ & $138.4 \pm 7.2$ & $88.8 \pm 5.6$ & $109.8 \pm 6.5$ \\
\hline & D30 $(n=9)$ & $118 \pm 11.8$ & $140.1 \pm 7.2$ & $90.1 \pm 6.3$ & $108.2 \pm 6.7$ \\
\hline & D90 $(n=8)$ & $139 \pm 12.2$ & $139.2 \pm 9.3$ & $97.7 \pm 9.7$ & $114.0 \pm 9.5$ \\
\hline & $\mathrm{D} 180(\mathrm{n}=7)$ & $131 \pm 10.2$ & $138.2 \pm 4.7$ & $89.8 \pm 6.6$ & $111.0 \pm 4.3$ \\
\hline
\end{tabular}

Data are presented as mean \pm SEM; heart rate was obtained from holter recording. $D$ day; $S B P$ systolic blood pressure; $D B P$ diastolic blood pressure; $M B P$ mean blood pressure.

measurement $(n=1)$. Only one dog in sildenafil group was reached the endpoint by increased stage of MMVD after obtained the data at day 90 .

\section{Clinical examination}

No major systemic diseases that affected cardiac function were found in all dogs. The intensity of heart murmur was showed in Table 3. In this study, the grades in all MMVD groups were grade II/VI to grade IV/VI. The baseline HR, systolic (SBP), diastolic (DBP) and mean blood pressures (MBP) of the study population were also summarized in Table 3. The results showed that MMVD dogs had significant higher average resting heart rate $(22.9 \%)$ when compared with healthy dogs $(P<0.05)$. In addition, there was no significant difference in HR among subgroup of MMVD dogs. The average SBP, DBP and MBP at baseline in the MMVD dogs were higher than the healthy dogs $(134.1 \pm 3.6$ vs. $114.3 \pm 4.0 \mathrm{mmHg}, P<0.01 ; 87.0 \pm 2.9$ vs. $65.7 \pm 3.4 \mathrm{mmHg}, P<0.01 \mathrm{and} 107.0$ \pm 3.2 vs. $81.9 \pm 3.1 \mathrm{mmHg} ; P<0.01$, respectively).

The average resting HR, SBP, DBP and MABP at days 0, 30, 90 and 180 in MMVD dogs were obtained (Table 4). No significant difference was observed for the average HR of MMVD dogs between days 0, 30, 90 and 180 of the study period. In addition, there was no significant difference in all blood pressures parameters among subgroups of MMVD dogs.

The results of electrocardiographic changes in MMVD dogs were also obtained (Table 5). No significant difference was found for all ECG parameters of MMVD dogs measured at days 0, 30, 90 and 180 of the study period.

\section{Time- and frequency-domain analysis of heart rate variability in control and study groups}

Time domain analysis of heart rate variability: The results of time domain analysis of HRV were shown in Tables 6 and 7. MMVD dogs had significantly decreased NNA (17.8\%; Healthy 637.9 \pm 24.3 msec vs MMVD 524.1 \pm 18.0 msec), SDNN (21.6\%; 
Table 5. ECG parameters of Control, Sildenafil and Enalapril groups of dogs with myxomatous mitral valve degeneration (MMVD) measured at days $0,30,90$ and 180

\begin{tabular}{llllllll}
\hline & ECG parameters & HR $(\mathrm{bpm})$ & RR $(\mathrm{msec})$ & PQ $(\mathrm{msec})$ & QRS $(\mathrm{msec})$ & QT $(\%)$ & QTcV $(\mathrm{msec})$ \\
\hline D0 & Control $(\mathrm{n}=13)$ & $116 \pm 7.8$ & $556.2 \pm 44.0$ & $96.1 \pm 5.0$ & $49.1 \pm 2.0$ & $191.5 \pm 4.2$ & $191.6 \pm 4.2$ \\
& Sildenafil $(\mathrm{n}=12)$ & $110 \pm 5.2$ & $577.0 \pm 26.6$ & $87.9 \pm 4.0$ & $46.4 \pm 1.9$ & $186.4 \pm 4.4$ & $186.5 \pm 4.4$ \\
& Enalapril (n=9) & $107 \pm 8.5$ & $606.2 \pm 51.0$ & $87.1 \pm 4.6$ & $54.9 \pm 3.1$ & $188.4 \pm 6.0$ & $188.4 \pm 6.0$ \\
\hline D30 & Control (n=13) & $114 \pm 7.9$ & $565.5 \pm 40.3$ & $93.3 \pm 5.0$ & $52.6 \pm 1.9$ & $189.2 \pm 4.8$ & $189.3 \pm 4.8$ \\
& Sildenafil (n=12) & $106 \pm 5.9$ & $607.7 \pm 34.8$ & $89.5 \pm 4.1$ & $52.5 \pm 2.4$ & $189.4 \pm 5.9$ & $189.5 \pm 5.9$ \\
& Enalapril (n=9) & $122 \pm 9.8$ & $533.4 \pm 46.3$ & $88.0 \pm 4.6$ & $54.0 \pm 2.6$ & $185.1 \pm 6.3$ & $185.2 \pm 6.3$ \\
\hline D90 & Control (n=12) & $106 \pm 4.9$ & $596.4 \pm 29.8$ & $93.5 \pm 4.3$ & $51.8 \pm 2.2$ & $191.8 \pm 4.0$ & $191.9 \pm 4.0$ \\
& Sildenafil (n=12) & $105 \pm 6.3$ & $619.4 \pm 39.3$ & $87.0 \pm 4.6$ & $51.7 \pm 2.0$ & $187.9 \pm 4.5$ & $188.0 \pm 4.5$ \\
& Enalapril (n=8) & $121 \pm 9.9$ & $539.8 \pm 47.9$ & $85.2 \pm 3.7$ & $51.3 \pm 3.4$ & $185.2 \pm 5.9$ & $185.2 \pm 5.9$ \\
\hline D180 & Control (n=8) & $103 \pm 7.1$ & $630.0 \pm 45.2$ & $100.1 \pm 5.3$ & $50.4 \pm 1.5$ & $199.4 \pm 3.6$ & $199.5 \pm 3.6$ \\
& Sildenafil (n=11) & $108 \pm 3.4$ & $581.9 \pm 22.5$ & $88.2 \pm 3.9$ & $53.9 \pm 1.5$ & $186.0 \pm 2.8$ & $186.7 \pm 2.9$ \\
& Enalapril (n=7) & $115 \pm 6.9$ & $563.6 \pm 46.6$ & $77.5 \pm 4.1$ & $50.9 \pm 2.3$ & $193.3 \pm 9.4$ & $193.4 \pm 9.4$ \\
\hline
\end{tabular}

Data are presented as mean \pm SEM. $n$ number; $D$ day; $H R$ heart rate; $R R$ the onset of the peak of $\mathrm{R}$ wave and ends at the peak of next $\mathrm{R}$ wave; $P Q$; the onset of the $\mathrm{P}$ wave and ends at the onset of the $\mathrm{Q}$ wave; $Q R S$ the onset of the $\mathrm{Q}$ wave and ends at the endpoint of the $\mathrm{S}$ wave; $Q T$ the onset of the QRS complex and ends at the endpoint of the T wave; QTcV QT intervals were rate-corrected by the methods of Van de Water.

Table 6. Time domain analysis parameters of heart rate variability between myxomatous mitral valve degeneration and healthy dogs at baseline (D0)

\begin{tabular}{ccccccc}
\hline \multirow{2}{*}{ Groups } & \multicolumn{7}{c}{ Parameters } \\
\cline { 2 - 7 } & $\begin{array}{c}\text { NNA } \\
(\mathrm{msec})\end{array}$ & $\begin{array}{c}\text { SDNN } \\
(\mathrm{msec})\end{array}$ & $\begin{array}{c}\text { SDANN } \\
(\mathrm{msec})\end{array}$ & $\begin{array}{c}\text { SDNN index } \\
(\mathrm{msec})\end{array}$ & $\begin{array}{c}\text { pNN50 } \\
(\%)\end{array}$ & $\begin{array}{c}\text { rMSSD } \\
(\mathrm{msec})\end{array}$ \\
\hline Healthy dogs $(\mathrm{n}=13)$ & $637.9 \pm 24.3$ & $150.3 \pm 10.9$ & $76.7 \pm 12.6$ & $128.7 \pm 9.4$ & $46.9 \pm 5.1$ & $133.1 \pm 9.4$ \\
MMVD dogs $(\mathrm{n}=34)$ & $524.1 \pm 18.0^{\mathrm{b})}$ & $117.8 \pm 9.0^{\mathrm{a})}$ & $57.6 \pm 7.9$ & $106.6 \pm 10.2$ & $33.6 \pm 4.0^{\mathrm{a})}$ & $112.8 \pm 10.3$ \\
\hline
\end{tabular}

Data are presented as mean \pm SEM. a) $P<0.05$ and b) $P<0.01$ compared with healthy group, $N N A$ the average of normal sinus RR intervals in the entire recording; $S D N N$ standard deviation of all normal sinus RR intervals in the entire recording; SDANN standard deviation of the average of normal sinus RR intervals in division of the entire recording; SDNN index the average of the standard deviation of all normal sinus RR intervals in division of the entire recording; $p N N 50$ the percentage of the number of normal-to-normal sinus RR intervals with differences $>50$ msec computed over the entire recording; $r M S S D$ square root of the average of the squared differences between adjacent normal sinus RR intervals over the entire recording.

Table 7. Time domain analysis parameters of HRV in control subgroup and in sildenafil and enalapril treatment subgroups of myxomatous mitral valve degeneration (MMVD) dogs at days 0, 30, 90 and 180

\begin{tabular}{|c|c|c|c|c|c|c|c|}
\hline \multicolumn{2}{|c|}{ Time domain parameters } & \multirow{2}{*}{$\begin{array}{c}\begin{array}{c}\text { NNA } \\
(\mathrm{msec})\end{array} \\
545.6 \pm 26.5\end{array}$} & \multirow{2}{*}{$\begin{array}{c}\begin{array}{c}\text { SDNN } \\
(\mathrm{msec})\end{array} \\
116.5 \pm 15.8\end{array}$} & \multirow{2}{*}{$\begin{array}{c}\begin{array}{c}\text { SDANN } \\
(\mathrm{msec})\end{array} \\
63.3 \pm 15.6\end{array}$} & \multirow{2}{*}{$\begin{array}{c}\text { SDNN index } \\
(\mathrm{msec})\end{array}$} & \multirow{2}{*}{$\begin{array}{c}\begin{array}{c}\mathrm{pNN} 50 \\
(\%)\end{array} \\
32.4 \pm 6.3\end{array}$} & \multirow{2}{*}{$\begin{array}{c}\begin{array}{c}\text { rMSSD } \\
(\mathrm{msec})\end{array} \\
106.9 \pm 14.9\end{array}$} \\
\hline D0 & Control $(\mathrm{n}=13)$ & & & & & & \\
\hline & Sildenafil $(n=12)$ & $538.5 \pm 34.0$ & $134.1 \pm 16.0$ & $57.2 \pm 12.4$ & $120.7 \pm 20.4$ & $41.4 \pm 7.1$ & $131.4 \pm 19.3$ \\
\hline & Enalapril $(n=9)$ & $475.2 \pm 32.3$ & $99.8 \pm 17.5$ & $44.2 \pm 12.2$ & $95.9 \pm 20.3$ & $24.4 \pm 7.2$ & $99.2 \pm 20.6$ \\
\hline \multirow[t]{3}{*}{ D30 } & Control $(n=13)$ & $-1.3 \pm 5.4$ & $18.5 \pm 13.0$ & $125.9 \pm 71.4$ & $12.2 \pm 12.6$ & $29.8 \pm 27.4$ & $16.5 \pm 15.0$ \\
\hline & Sildenafil $(n=12)$ & $12.3 \pm 7.8$ & $40.4 \pm 22.4$ & $380.6 \pm 260.5$ & $151.6 \pm 106.4$ & $246.1 \pm 225.5$ & $57.5 \pm 30.6$ \\
\hline & Enalapril $(\mathrm{n}=9)$ & $16.4 \pm 10.0$ & $32.1 \pm 24.5$ & $158.1 \pm 158.5$ & $41.0 \pm 33.7$ & $371.7 \pm 322.2$ & $41.6 \pm 35.7$ \\
\hline \multirow[t]{3}{*}{ D90 } & Control $(\mathrm{n}=12)$ & $-0.7 \pm 5.5^{\mathrm{ab})}$ & $1.0 \pm 8.4^{\mathrm{a})}$ & $30.3 \pm 30.4$ & $-2.2 \pm 10.5^{\mathrm{a})}$ & $10.6 \pm 22.2^{\text {a) }}$ & $0.2 \pm 10.7^{\mathrm{a})}$ \\
\hline & Sildenafil $(n=12)$ & $15.4 \pm 7.9^{b)}$ & $41.4 \pm 20.8^{b)}$ & $178.7 \pm 126.6$ & $277.0 \pm 241.8^{b)}$ & $148.6 \pm 106.3^{b)}$ & $64.8 \pm 31.3^{\mathrm{b})}$ \\
\hline & Enalapril $(\mathrm{n}=8)$ & $-1.6 \pm 5.9^{\mathrm{a})}$ & $-17.9 \pm 10.3^{\text {a) }}$ & $62.9 \pm 90.6$ & $-19.5 \pm 12.4^{\text {a) }}$ & $56.3 \pm 80.1^{\text {a) }}$ & $-20.5 \pm 12.6^{a)}$ \\
\hline \multirow[t]{3}{*}{ D180 } & Control $(\mathrm{n}=8)$ & $23.2 \pm 9.4^{\mathrm{a})}$ & $74.9 \pm 30.9$ & $113.2 \pm 78.2$ & $63.0 \pm 33.8$ & $237.3 \pm 137.3$ & $75.7 \pm 25.9$ \\
\hline & Sildenafil $(\mathrm{n}=11)$ & $7.7 \pm 12.5^{\mathrm{ab})}$ & $24.7 \pm 29.1$ & $346.2 \pm 261.6$ & $105.4 \pm 81.4$ & $371.3 \pm 378.4$ & $27.3 \pm 33.3$ \\
\hline & Enalapril $(n=7)$ & $6.2 \pm 8.5^{\mathrm{b})}$ & $30.7 \pm 22.0$ & $341.8 \pm 239.8$ & $26.4 \pm 23.4$ & $314.3 \pm 313.1$ & $28.8 \pm 26.1$ \\
\hline
\end{tabular}

Data are presented as mean \pm SEM, actual values were presented at D0 while\% change from baseline were presented at D30, 90 and 180 . a,b) compared among groups at the same time-point, statistical difference $(P<0.05), D$ day; $N N A$ the average of normal sinus RR intervals in the entire recording; $S D N N$ standard deviation of all normal sinus RR intervals in the entire recording; $S D A N N$ standard deviation of the average of normal sinus RR intervals in division of the entire recording; $S D N N$ index the average of the standard deviation of all normal sinus RR intervals in division of the entire recording; $p N N 50$ the percentage of the number of normal-to-normal sinus RR intervals with differences $>50$ msec computed over the entire recording; $r M S S D$ square root of the average of the squared differences between adjacent normal sinus RR intervals over the entire recording. 
Table 8. Frequency domain analysis parameters of myxomatous mitral valve degeneration (MMVD) and healthy dogs at baseline (D0)

\begin{tabular}{ccccc}
\hline \multirow{2}{*}{ Groups } & \multicolumn{4}{c}{ Parameters } \\
\cline { 2 - 5 } & $\mathrm{LF}\left(\mathrm{msec}^{2}\right)$ & $\mathrm{HF}\left(\mathrm{msec}^{2}\right)$ & $\mathrm{TP}\left(\mathrm{msec}^{2}\right)$ & $\mathrm{LF} / \mathrm{HF}$ \\
\hline Healthy dogs $(\mathrm{n}=13)$ & $2,356.5 \pm 197.4$ & $7,204.9 \pm 1,525.1$ & $16,919.0 \pm 2,281.6$ & $0.44 \pm 0.06$ \\
MMVD dogs $(\mathrm{n}=34)$ & $2,447.7 \pm 397.7$ & $8,243.6 \pm 2,323.2$ & $16,477.0 \pm 3,091.9$ & $1.01 \pm 0.16^{\mathrm{a})}$ \\
\hline
\end{tabular}

Data are presented as mean \pm SEM. a) $P<0.05$ compared with healthy group, $M M V D$ myxomatous mitral valve degeneration; $H R V$ heart rate variability; $L F$ low frequency; $H F$ high frequency; $T P$ total power; $L F / H F$ ratio of LF power and $H F$ power.

Table 9. Frequency domain analysis parameters of HRV in control subgroup and after sildenafil and enalapril treatments subgroups of myxomatous mitral valve degeneration (MMVD) dogs measured at days 0, 30, 90 and 180

\begin{tabular}{|c|c|c|c|c|c|}
\hline \multicolumn{2}{|c|}{ Frequency domain parameters } & \multirow{2}{*}{$\begin{array}{c}\mathrm{LF}\left(\mathrm{msec}^{2}\right) \\
1,992.8 \pm 350.0\end{array}$} & \multirow{2}{*}{$\begin{array}{c}\mathrm{HF}\left(\mathrm{msec}^{2}\right) \\
4,785.7 \pm 2,035.5\end{array}$} & \multirow{2}{*}{$\begin{array}{c}\mathrm{TP}\left(\mathrm{msec}^{2}\right) \\
12,714.3 \pm 3,587.6\end{array}$} & \multirow{2}{*}{$\begin{array}{c}\mathrm{LF} / \mathrm{HF} \\
1.01 \pm 0.23\end{array}$} \\
\hline D0 & Control $(\mathrm{n}=13)$ & & & & \\
\hline & Sildenafil $(\mathrm{n}=12)$ & $2,557.6 \pm 373.6$ & $11,649.1 \pm 4,195.8$ & $20,717.7 \pm 5,114.4$ & $1.01 \pm 0.31$ \\
\hline & Enalapril $(\mathrm{n}=9)$ & $2,958.3 \pm 1,336.5$ & $8,697.7 \pm 5,289.5$ & $16,257.6 \pm 7,182.5$ & $1.00 \pm 0.26$ \\
\hline \multirow[t]{3}{*}{ D30 } & Control $(n=13)$ & $21.4 \pm 19.6$ & $150.5 \pm 83.0$ & $56.6 \pm 32.2$ & $-11.6 \pm 17.8$ \\
\hline & Sildenafil $(\mathrm{n}=12)$ & $72.1 \pm 44.0$ & $1,085.4 \pm 845.7$ & $231.6 \pm 145.2$ & $-14.8 \pm 25.3$ \\
\hline & Enalapril $(\mathrm{n}=9)$ & $21.5 \pm 37.6$ & $1,394.3 \pm 1,321.5$ & $206.5 \pm 178.7$ & $11.8 \pm 46.3$ \\
\hline \multirow[t]{3}{*}{ D90 } & Control $(\mathrm{n}=12)$ & $-3.8 \pm 15.6^{\mathrm{a})}$ & $82.9 \pm 71.3^{\mathrm{a})}$ & $23.8 \pm 31.3^{\mathrm{a})}$ & $8.5 \pm 22.9$ \\
\hline & Sildenafil $(n=12)$ & $127.1 \pm 51.4^{\mathrm{b})}$ & $414.2 \pm 152.4^{\mathrm{b})}$ & $197.0 \pm 75.0^{\mathrm{b})}$ & $-22.4 \pm 21.8$ \\
\hline & Enalapril $(\mathrm{n}=8)$ & $-15.2 \pm 24.3^{\mathrm{a})}$ & $-15.6 \pm 38.8^{\text {a) }}$ & $-32.4 \pm 22.4^{a)}$ & $163.7 \pm 120.6$ \\
\hline \multirow[t]{3}{*}{ D180 } & Control $(n=8)$ & $63.1 \pm 34.7$ & $678.9 \pm 363.5$ & $227.5 \pm 83.0$ & $-54.8 \pm 13.9$ \\
\hline & Sildenafil $(n=11)$ & $95.7 \pm 76.3$ & $999.1 \pm 869.5$ & $185.4 \pm 157.6$ & $127.6 \pm 87.0$ \\
\hline & Enalapril $(\mathrm{n}=7)$ & $4.0 \pm 20.4$ & $280.5 \pm 292.3$ & $38.9 \pm 47.4$ & $64.0 \pm 59.1$ \\
\hline
\end{tabular}

Data are presented as mean \pm SEM, actual values were presented at D0 while $\%$ change from baseline were presented at D30, 90 and 180. a,b) compared among groups at the same time-point, statistical difference $(P<0.05), H R V$ heart rate variability; $L F$ low frequency; $H F$ high frequency; $T P$ total power; $L F / H F$ ratio of $L F$ power and HF power.

Healthy $150.3 \pm 10.9 \mathrm{msec}$ vs MMVD $117.8 \pm 9.4 \mathrm{msec})$ and pNN50 (24.1\%; Healthy $46.9 \pm 5.1 \mathrm{msec}$ vs MMVD $33.6 \pm 4.0$ msec) when compared with Healthy dogs $(P<0.05)$. When compared within the MMVD dogs at the same time-point of the study period, no time domain parameters were different among subgroups of MMVD dogs measured at D0 and D30. After treatment with sildenafil for 90 days, the NNA values were highest and significantly different from dogs receiving enalapril $(P<0.05)$. In addition, the SDNN, SDNN index, pNN50 and rMSSD were significant higher in MMVD dogs receiving sildenafil when compared with the control and enalapril group $(P<0.05)$. At Day 180 , the NNA of dogs receiving enalapril was significantly lower than control dogs.

Frequency domain analysis of heart rate variability: The results of frequency domain analysis of HRV were shown in Tables 8, 9 and Fig. 1. MMVD dogs had significant increased LF/HF (129.5\%; Healthy $0.44 \pm 0.06$ vs MMVD $1.01 \pm 0.16)$ when compared with healthy dogs $(P<0.05)$ but no significant differences were found for LF, HF and TP. When compared within the MMVD groups at the same time-point of the study periods, there were no significant differences in LF, HF, TP and LF/HF among subgroups of MMVD dogs at days 0, 30 and 180. After treatment for 90 days, LF, HF and TP values were highest in MMVD dogs receiving sildenafil and these data were significantly higher when compared with the control and enalapril groups $(P<0.05)$. The $\mathrm{LF} / \mathrm{HF}$ value of dogs receiving sildenafil was lowest but it does not achieve statistical significance when compared with control and enalapril groups.

\section{DISCUSSION}

The principal goal of this study was to assess the chronic effects of sildenafil on time- and frequency-domain parameters of HRV in class B1 or B2 MMVD dogs in comparison with enalapril treatment. Heart rate variability is the variation of beat-tobeat RR intervals of the electrocardiograms and indicates the fluctuations of heart rate. It has been established as a noninvasive tool for monitoring balance of autonomic nervous control of the heart and has been proved to be clinically useful in evaluating cardiovascular responsiveness to alterations in autonomic nervous control [30].

The MMVD dogs used in the present study were client-owned dogs with ACVIM class B1 or B2 suggesting that they were in the early stages of mild MMVD. Similar to the previous studies, the most frequent breeds that affected MMVD dogs in the current study were small breed, middle- to old-aged dogs $[10,15,20]$. Therefore, it is suggested that middle- to old-aged, small breed dogs have higher risk to develop MMVD. A recognizable cardiac murmur of all of MMVD dogs used in this study was MR murmurs with intensity grade II/VI to grade IV/VI. It is well-known that the loudness of the murmur has been correlated with the severity of the valvular regurgitation and prognosis [13]. Recent study in MMVD dogs by López-Alvarez and colleagues [19] demonstrated 


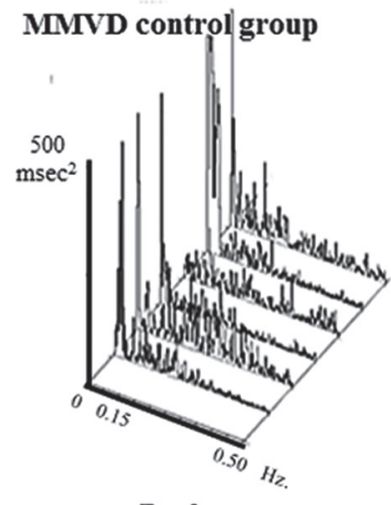

Day0

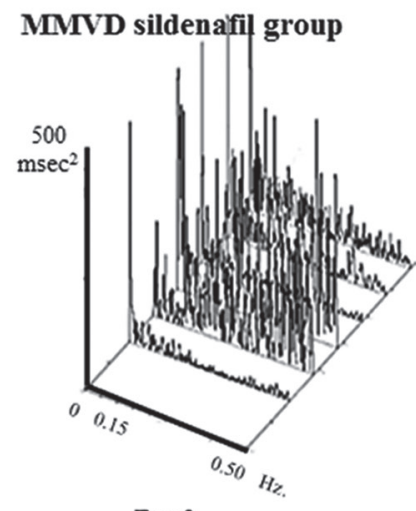

Day0

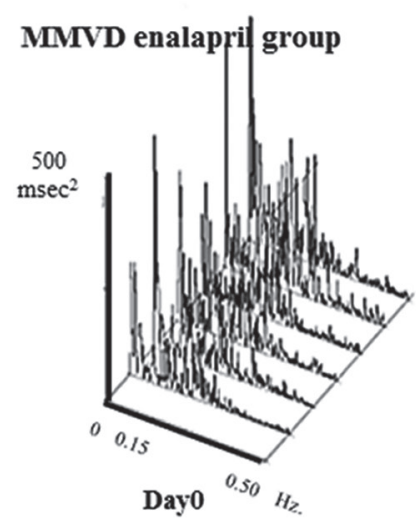

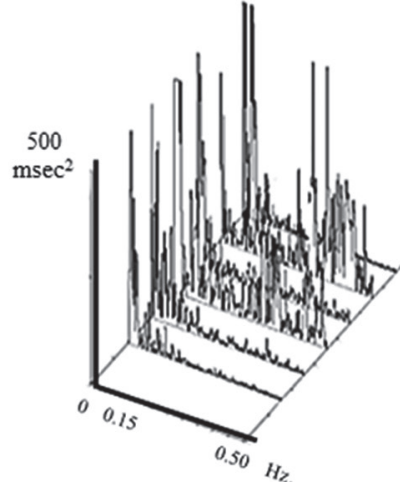

Day30

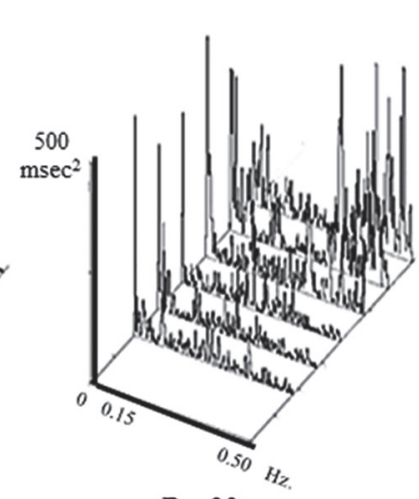

Day90

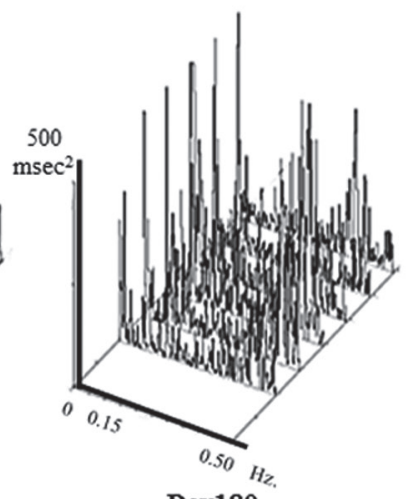

Day180
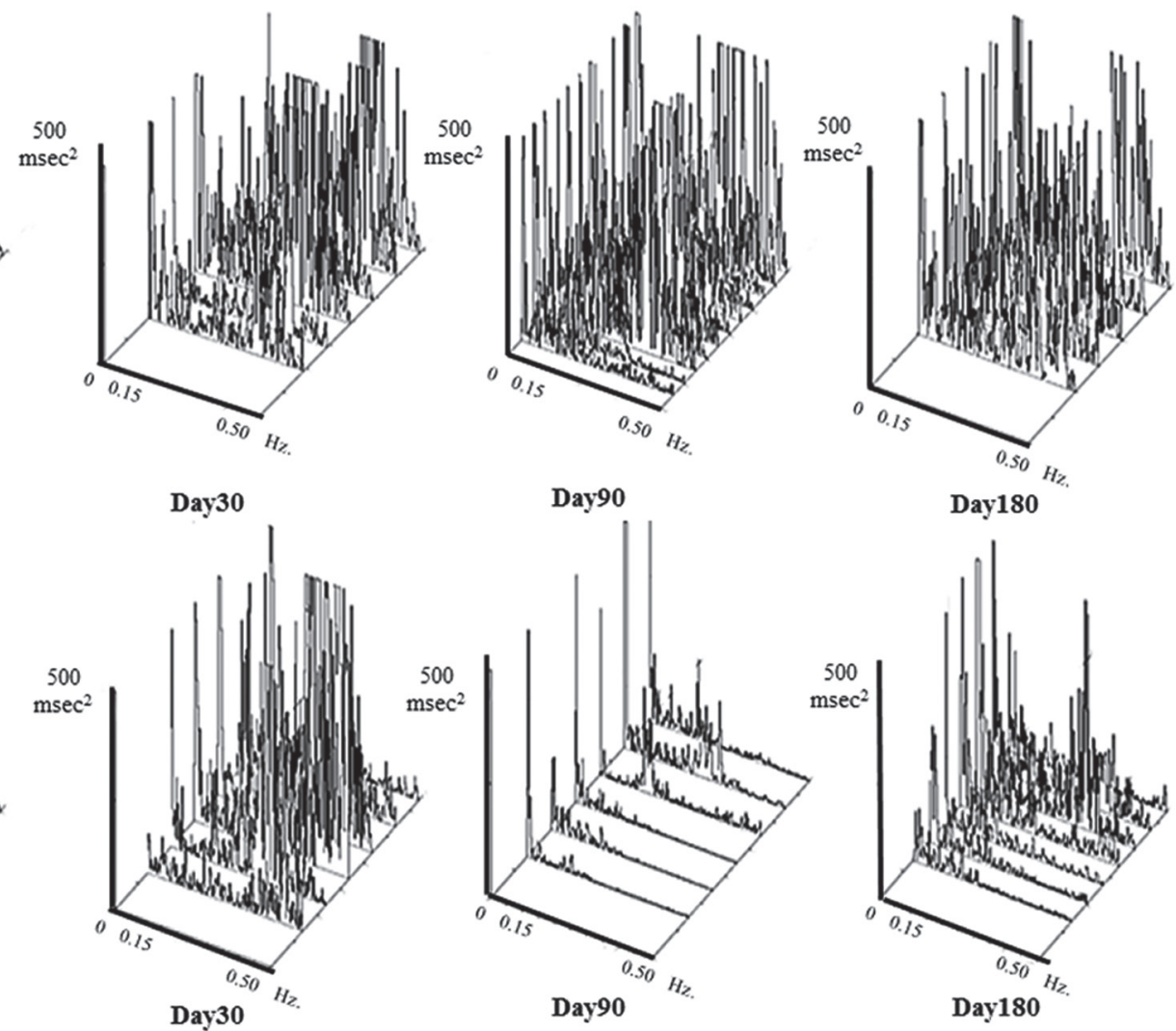

Fig. 1. The examples of power spectral density of one dog in each myxomatous mitral valve degeneration (MMVD) group at Day $0,30,90$ and 180 of study period, Y-bar represents power spectral density at $500 \mathrm{~ms}^{2}$ and X-bar represents frequency range of $0-0.5 \mathrm{~Hz}$.

that heart murmur intensity louder than III/VI together with history of cough, exercise intolerance, decrease appetite, syncope and absence of respiratory sinus arrhythmia were associated with the worse outcomes.

It has been known that alterations resulted from MR affect HR, blood pressure and HRV. The increase in both HR and blood pressure in MMVD dogs were observed in the present study. The increase in HR may result from increased sympathetic activity or reduced parasympathetic activity (i.e. vagal inhibition) or both processes [31]. The SBP, MBP and DBP in our MMVD dogs were significantly higher than those in healthy dogs which may result from both increase sympathetic tone and neurohormonal activation; however, those values were within normal limits. Similar observation was found in previous study in small-breed, MMVD dogs with different International Small Animal Cardiac Heath Council (ISACHC) heart failure classes demonstrated higher SBP, but still within the reference range, when compared to healthy dogs [22].

This study demonstrated that asymptomatic MMVD dogs have impaired cardiac autonomic activities when compared with healthy dogs as suggested by significantly decreased NNA, SDNN and pNN50, and increased LF/HF parameters. NNA, SDNN and pNN50 are parameters derived from time domain analysis of HRV whereas the LF/HF is derived from frequency domain analysis of HRV. It has been known in MMVD dogs that a decrease in NNA reflects an increase in heart rate and related to severity of MMVD [24]. The 
decrease in SDNN reflects a reduction of standard deviation of the NN interval implying a reduction of parasympathetic tone. In the present study, pNN50 was significantly decreased in MMVD dogs which similar to previous study observed in dogs with MMVD that developed heart failure [21]. In that study, the pNN50 was noticeably decreased related to low high frequency suggesting the withdrawal of parasympathetic tone in those MMVD dogs [20]. The present study also showed that the ratio of LF to HF was increased which has been used as a marker of sympathovagal imbalance [2, 8]. This finding was supported by previous study in dogs with mild MR in which the LF/HF was increased significantly due to a reduction of high frequency [14].

To our knowledge, this is the first study that assessed the long-term effect of sildenafil and enalapril on both time- and frequency-domain indices of HRV in asymptomatic MMVD dogs. The significant finding of our study is that long-term treatment with sildenafil (at least 90 days) improves HRV suggesting the sympathovagal balance was restored in those dogs. The increase in parasympathetic modulation and improved sympathovagal imbalance in dogs with asymptomatic MMVD dogs in the present study supported by increased NNA, SDNN, SDNN index, pNN50 and rMSSD of time domains parameters and LF, HF and TP values of frequency domains parameters of HRV. The LF reflects both sympathetic and parasympathetic tones whereas the HF represents predominantly parasympathetic activity. These changes of frequency domain indices were correlated with the time domain parameters. Short-term treatment with enalapril has been previously studied in MMVD dogs [10]. That study demonstrated beneficial effects of enalapril to decrease sympathetic tone while increase parasympathetic activity and corresponded to the reduction in preload and afterload. However, our results indicated that long-term treatment with enalapril did not improve HRV in mild MMVD dogs. The possible reasons would be the differences of duration of therapy (short-term vs long-term) and stage of heart failure since that study enrolled more dogs in class B2 than the current study. Another possible reason would be the compartments of RASS (i.e. circulating RAAS vs local tissue RAAS) [9]. It was suggested that effects of short-term therapy (i.e. acute hemodynamic responses, reduction in ventricular filling pressure and reduced vascular resistance) are related to plasma renin activity whereas the effects of long-term therapy are related to individual organ responses [12].

The effect of sildenafil on HRV has not been study in dogs; however, the effect of single oral dose of sildenafil reported in healthy men demonstrated no notable influence on the low and high frequency of HRV analysis [1, 28]. In veterinary medicine, sildenafil has been used for treatment of pulmonary hypertension [17]. In dogs with moderate to severe MR together with pulmonary hypertension, sildenafil has been shown to improve clinical score. In several animal models of CHF due to volume or pressure overload, sildenafil has demonstrated effects of antiapoptotic and improved cardiac function [27]. Hence, the possible mechanisms of sildenafil that improves HRV in this study might be due to its cardioprotection (i.e. promote reverse remodeling, reduce myocardial apoptosis and hypertrophy) as suggested by several investigators [18, 25, 27, 29].

Although effects of sildenafil on HRV parameters measured at 90 days after treatment were significantly better than the other groups (the control and enalapril), the effects of sildenafil measured at 180 days did not achieve statistical significance. This is because 5 dogs in the control group have reached the end point earlier than the end of experiment (i.e. development of clinical signs of congestive heart failure). Those 5 dogs also have worse HRV parameters when compared with the remaining 8 dogs in the control group; therefore, when those 5 dogs were removed after D90, the percent change from baseline of some HRV parameters in the control group at D180 seem to be improved dramatically (i.e. NNA, LF/HF).

Reduction in several HRV indices reflects sympathovagal imbalance had been identified as risk factors for sudden cardiac death (SCD) in human patients [26]. One study in CHF suggested that each $10 \mathrm{msec}$ increase in the SDNN could reduce the mortality rate by $20 \%$ [5]. These studies implied that patients with reduced HRV indices have poor prognosis. Based on human medicine, we suggest that the HRV in MMVD dogs should be restored to improve sympathovagal balance.

This study has certain limitations. First, the study was not a double-blind, randomized design. Second, the sample size of the present study was quite small and there was no follow up beyond 180 days. However, our results might be still widely applicable for asymptomatic MMVD dogs as the sildenafil will help with improvement of sympathoval balance. Further large clinical trial with double-blind randomized design may help to support ensure our findings.

In conclusion, the indices of time domain analysis were significantly decreased while the ratio of LF to HF of frequency domain analysis was increased in MMVD dogs when compared with healthy dogs suggesting parasympathetic withdrawal and/or sympathetic activation. Asymptomatic MMVD dogs (i.e. ACVIM class B1/B2) treated with sildenafil had increased cardiac autonomic modulation. The changes of HRV indices in dogs treated with sildenafil also suggested that the increase of parasympathetic activity is over the sympathetic activity. Therefore, sildenafil may be useful for maintaining normal autonomic nerve activity in dogs with asymptomatic MMVD.

CONFLICT OF INTEREST. The authors declare that they have no conflict of interest.

ACKNOWLEDGMENTS. The authors would like to thank Ratchadapiseksomphot Endowment Fund (Health: CU-56-645-HR), Chulalongkorn University, Bangkok, Thailand.

\section{REFERENCES}

1. Agelink, M. W., Ullrich, H. and Brockmeyer, N. H. 2001. Sildenafil does not influence autonomic neurocardiac control assessed by standard measurements of heart rate variability. Circulation 104: E145. [Medline]

2. Atkins, C., Bonagura, J., Ettinger, S., Fox, P., Gordon, S., Haggstrom, J., Hamlin, R., Keene, B., Luis-Fuentes, V. and Stepien, R. 2009. Guidelines for the diagnosis and treatment of canine chronic valvular heart disease. J. Vet. Intern. Med. 23: 1142-1150. [Medline] [CrossRef] 
3. Atkins, C. E. and Häggström, J. 2012. Pharmacologic management of myxomatous mitral valve disease in dogs. J. Vet. Cardiol. 14: $165-184$. [Medline] [CrossRef]

4. Atkins, C. E., Keene, B. W., Brown, W. A., Coats, J. R., Crawford, M. A., DeFrancesco, T. C., Edwards, N. J., Fox, P. R., Lehmkuhl, L. B., Luethy, M. W., Meurs, K. M., Petrie, J. P., Pipers, F. S., Rosenthal, S. L., Sidley, J. A. and Straus, J. H. 2007. Results of the veterinary enalapril trial to prove reduction in onset of heart failure in dogs chronically treated with enalapril alone for compensated, naturally occurring mitral valve insufficiency. $J$. Am. Vet. Med. Assoc. 231: 1061-1069. [Medline] [CrossRef]

5. Bilchick, K. C., Fetics, B., Djoukeng, R., Fisher, S. G., Fletcher, R. D., Singh, S. N., Nevo, E. and Berger, R. D. 2002. Prognostic value of heart rate variability in chronic congestive heart failure (Veterans Affairs' Survival Trial of Antiarrhythmic Therapy in Congestive Heart Failure). Am. $J$. Cardiol. 90: 24-28. [Medline] [CrossRef]

6. Boon, J. A. 2011. Evaluation of size, function and hemodynamic. pp. 153-266. In: Veterinary Echocardiography. 2nd ed. (Boon J. A. ed), WileyBlackwell, Chichester.

7. Brown, A. J., Davison, E. and Sleeper, M. M. 2010. Clinical efficacy of sildenafil in treatment of pulmonary arterial hypertension in dogs. J. Vet. Intern. Med. 24: 850-854. [Medline] [CrossRef]

8. Calvert, C. A. 1998. Heart rate variability. Vet. Clin. North Am. Small Anim. Pract. 28: 1409-1427, viii. [Medline] [CrossRef]

9. Campbell, D. J. 2014. Clinical relevance of local Renin Angiotensin systems. Front. Endocrinol. (Lausanne) 5: 113. [Medline]

10. Chompoosan, C., Buranakarl, C., Chaiyabutr, N. and Chansaisakorn, W. 2014. Decreased sympathetic tone after short-term treatment with enalapril in dogs with mild chronic mitral valve disease. Res. Vet. Sci. 96: 347-354. [Medline] [CrossRef]

11. Dai, W. and Kloner, R. A. 2012. Is inhibition of phosphodiesterase type 5 by sildenafil a promising therapy for volume-overload heart failure? Circulation 125: 1341-1343. [Medline] [CrossRef]

12. De Mello, W. C. and Frohlich, E. D. 2014. Clinical perspectives and fundamental aspects of local cardiovascular and renal Renin-Angiotensin systems. Front. Endocrinol. (Lausanne) 5: 16. [Medline]

13. Desjardins, V. A., Enriquez-Sarano, M., Tajik, A. J., Bailey, K. R. and Seward, J. B. 1996. Intensity of murmurs correlates with severity of valvular regurgitation. Am. J. Med. 100: 149-156. [Medline] [CrossRef]

14. Fujii, Y. and Wakao, Y. 2003. Spectral analysis of heart rate variability in dogs with mild mitral regurgitation. Am. J. Vet. Res. 64: 145-148. [Medline] [CrossRef]

15. Häggström, J., Höglund, K. and Borgarelli, M. 2009. An update on treatment and prognostic indicators in canine myxomatous mitral valve disease. J. Small Anim. Pract. 50 Suppl 1: 25-33. [Medline] [CrossRef]

16. Karcz, M., Chojnowska, L., Zareba, W. and Ruzyłło, W. 2003. Prognostic significance of heart rate variability in dilated cardiomyopathy. Int. J. Cardiol. 87: 75-81. [Medline] [CrossRef]

17. Kellum, H. B. and Stepien, R. L. 2007. Sildenafil citrate therapy in 22 dogs with pulmonary hypertension. J. Vet. Intern. Med. 21: $1258-1264$. [Medline] [CrossRef]

18. Kim, K. H., Kim, Y. J., Ohn, J. H., Yang, J., Lee, S. E., Lee, S. W., Kim, H. K., Seo, J. W. and Sohn, D. W. 2012. Long-term effects of sildenafil in a rat model of chronic mitral regurgitation: benefits of ventricular remodeling and exercise capacity. Circulation 125: 1390-1401. [Medline] [CrossRef]

19. López-Alvarez, J., Elliott, J., Pfeiffer, D., Chang, Y. M., Mattin, M., Moonarmart, W., Hezzell, M. J. and Boswood, A. 2015. Clinical severity score system in dogs with degenerative mitral valve disease. J. Vet. Intern. Med. 29: 575-581. [Medline] [CrossRef]

20. Oliveira, M. S., Muzzi, R. A., Araujo, R. B., Muzzi, L. A., Ferreira, D. F. and Silva, E. F. 2014. Heart rate variability and arrhythmias evaluated with Holter in dogs with degenerative mitral valve disease. Arq. Bras. Med. Vet. Zootec. 66: 425-432. [CrossRef]

21. Oliveira, M. S., Muzzi, R. A., Araújo, R. B., Muzzi, L. A., Ferreira, D. F., Nogueira, R. and Silva, E. F. 2012. Heart rate variability parameters of myxomatous mitral valve disease in dogs with and without heart failure obtained using 24-hour Holter electrocardiography. Vet. Rec. 170: 622. [Medline] [CrossRef]

22. Petit, A. M., Gouni, V., Tissier, R., Trehiou-Sechi, E., Misbach, C., Pouchelon, J. L., Lefebvre, H. P. and Chetboul, V. 2013. Systolic arterial blood pressure in small-breed dogs with degenerative mitral valve disease: a prospective study of 103 cases (2007-2012). Vet. J. 197: 830-835. [Medline] [CrossRef]

23. Pirintr, P., Chansaisakorn, W., Trisiriroj, M., Kalandakanond-Thongsong, S. and Buranakarl, C. 2012. Heart rate variability and plasma norepinephrine concentration in diabetic dogs at rest. Vet. Res. Commun. 36: 207-214. [Medline] [CrossRef]

24. Rasmussen, C. E., Falk, T., Zois, N. E., Moesgaard, S. G., Häggström, J., Pedersen, H. D., Ablad, B., Nilsen, H. Y. and Olsen, L. H. 2012. Heart rate, heart rate variability, and arrhythmias in dogs with myxomatous mitral valve disease. J. Vet. Intern. Med. 26: 76-84. [Medline] [CrossRef]

25. Salloum, F. N., Abbate, A., Das, A., Houser, J. E., Mudrick, C. A., Qureshi, I. Z., Hoke, N. N., Roy, S. K., Brown, W. R., Prabhakar, S. and Kukreja, R. C. 2008. Sildenafil (Viagra) attenuates ischemic cardiomyopathy and improves left ventricular function in mice. Am. J. Physiol. Heart Circ. Physiol. 294: H1398-H1406. [Medline] [CrossRef]

26. Sandercock, G. R. and Brodie, D. A. 2006. The role of heart rate variability in prognosis for different modes of death in chronic heart failure. Pacing Clin. Electrophysiol. 29: 892-904. [Medline] [CrossRef]

27. Schwartz, B. G., Levine, L. A., Comstock, G., Stecher, V. J. and Kloner, R. A. 2012. Cardiac uses of phosphodiesterase-5 inhibitors. J. Am. Coll. Cardiol. 59: 9-15. [Medline] [CrossRef]

28. Siepmann, M., Rauh, R., Dill, O., Agelink, M. W. and Mueck-Weymann, M. 2007. The effects of sildenafil on heart rate variability in healthy subjects. J. Cardiovasc. Pharmacol. 50: 598-600. [Medline] [CrossRef]

29. Takimoto, E., Champion, H. C., Li, M., Belardi, D., Ren, S., Rodriguez, E. R., Bedja, D., Gabrielson, K. L., Wang, Y. and Kass, D. A. 2005. Chronic inhibition of cyclic GMP phosphodiesterase 5A prevents and reverses cardiac hypertrophy. Nat. Med. 11: 214-222. [Medline] [CrossRef]

30. Task Force of the European Society of Cardiology and the North American Society of Pacing and Electrophysiology. 1996. Heart rate variability. Standards of measurement, physiological interpretation, and clinical use. Eur. Heart J. 17: 354-381. [Medline] [CrossRef]

31. Vanderlei, L. C., Pastre, C. M., Hoshi, R. A., Carvalho, T. D. and Godoy, M. F. 2009. Basic notions of heart rate variability and its clinical applicability. Rev. Bras. Cir. Cardiovasc. 24: 205-217. [Medline] [CrossRef]

32. Wallis, R. M. 1999. The pharmacology of sildenafil, a novel and selective inhibitor of phosphodiesterase (PDE) type 5. Nippon Yakurigaku Zasshi 114 Suppl 1: 22P-26P. [Medline] [CrossRef]

33. Ware, W. A., Lund, D. D., Subieta, A. R. and Schmid, P. G. 1990. Sympathetic activation in dogs with congestive heart failure caused by chronic mitral valve disease and dilated cardiomyopathy. J. Am. Vet. Med. Assoc. 197: 1475-1481. [Medline] 